\title{
Materialidad y violencia a partir de la estructura original de la rareté en la Crítica de la razón dialéctica
}

\author{
Materiality and violence from the original \\ structure of the rareté in the Critique of \\ Dialectic Reason
}

\author{
MAXIMILIANO BASILIO CLADAKIS \\ Universidad Nacional de San Martín (Argentina) y CONICET
}

Recibido: 17/04/2017 Aceptado:02/11/2017

\begin{abstract}
RESUMEN
El presente estudio tiene por objetivo exponer la articulación entre violencia y materialidad a partir del fenómeno de la rareté como elemento original de la historia humana en la Crítica de la razón dialéctica. Con esta finalidad, el trabajo abordará la manera en que Jean Paul Sartre considera la institución de la historia humana desde una perspectiva dialéctica donde el hombre «hace» $\mathrm{y}$ «es hecho» por la historia. Desde esta perspectiva, la materia aparece como aquello que el hombre transforma a partir de su libre praxis pero también como aquello que transforma al hombre. En este sentido, es fundamental la forma en que la imposición de la materia es interiorizada por cada uno generando lazos intersubjetivos que se enmarcan en una lógica del conflicto en la que la que cada uno vive la presencia del otro como peligro de eliminación.

PALABRAS CLAVE

VIOLENCIA, DIALÉCTICA, SARTRE, MATERIALISMO, HISTORIA.
\end{abstract}

(C) Contrastes. Revista Internacional de Filosofía, vol. XXIII-Nº1 (2018), pp. 43-58. ISSN: 1136-4076

Departamento de Filosofía, Universidad de Málaga, Facultad de Filosofía y Letras

Campus de Teatinos, E-29071 Málaga (España) 


\section{ABSTRACT}

The present study aims to expose the articulation between violence and materiality from the phenomenon of rareté as an original element of human history in the Critique of Dialectical Reason. To this end, the work will address the way in which Jean Paul Sartre considers the institution of human history from a dialectical perspective where man «does» and «is made» by history. From this perspective, matter appears as that which man transforms from his free praxis but also as that which transforms man. In this sense, it is fundamental how the imposition of matter is internalized by each one creating intersubjective bonds that are framed in a logic of conflict in which each one lives the presence of the other as a danger of elimination.

KEYWORDS

VIOLENCE, DIALECTICS, SARTRE, MATERIALISM, HISTORY.

\section{INTRODUCCIÓN}

EL OBJETIVO DEL PRESENTE TRABAJO es abordar la articulación conceptual realizada por Jean Paul Sartre, en la Crítica de la razón dialéctica, entre la violencia y la materia, a partir de la comprensión de la historia humana como lucha contra la raretél. Considero que esta cuestión posee destacada relevancia en dos sentidos. Por un lado, es relevante en lo que hace a la problematización teórica contemporánea en torno a la violencia. En este sentido, las tesis de Sartre podrían agregar una serie de perspectivas a un debate que involucra a pensadores tales como Hanna Arendt, Walter Benjamin y Maurice MerleauPonty. Por otro lado, es relevante la forma en que Sartre trabaja la violencia y su relación con la historia y con la rareté ya que implica la emergencia de nuevos horizontes teóricos en el pensamiento del filósofo francés que, sin representar un quiebre absoluto, señalan un alejamiento con respecto a algunas de las premisas sostenidas en la obra de 1943. Con respecto a este punto, cabe mencionar que, muchas veces, la posición de Sartre en torno a la violencia es abordada a partir de la ontología fenomenológica expuesta en $E l$ ser y la nada, sobre todo a partir del capítulo «Las relaciones concretas con el otro», o a partir de sus ensayos histórico-políticos ${ }^{2}$, obviando el texto de

1 En el presente trabajo se ha optado por mantener la palabra en francés puesto que las traducciones varían. En la traducción al castellano realizada por Manuel Lamama, aparece traducida como «rareza» (Sartre 2004, p. 278). Sin embargo, algunos especialistas, como José Luís Rodríguez en su libro Sartre. La pasión por la libertad, la traducen como «escasez» (Cf. Rodríguez 2004, p. 114). Si bien considero más adecuada esta última traducción, el mantenimiento de la palabra en francés puede servir para presentar el concepto como un elemento constitutivo del pensamiento de Sartre cuya relevancia, muchas veces, no suele ser observada.

2 Sin lugar a dudas, el prólogo a Los condenados de la tierra es uno de los textos políticos que más se suele tener en cuenta para abordar el fenómeno de la violencia en el pensamiento sartreano. El más que interesante y sugestivo texto de Judith Buttler «Violencia, no violencia: Sartre sobre Fannon» trabaja esta cuestión de manera muy profunda. 
1960, cuando, es en este, donde se lleva a cabo la más compleja y detallada exposición en torno a la violencia y su posibilidad de intelección.

En las siguientes páginas, por lo tanto, se llevará a cabo una exposición acerca de la articulación de la violencia con la historia a partir de la estructura original de la rareté. Este último concepto es de una importancia nodal dentro de la Crítica de la razón dialéctica, tanto del primer tomo como del segundo, publicado de manera póstuma. La propia forma en que Sartre la denomina como estructura original es una manifestación de dicha importancia. La rareté es una impronta que marca a la historia humana al tiempo mismo que es su condición de posibilidad.

Ahora bien, con esta finalidad, el trabajo se dividirá en cuatro apartados. El primero girará en torno a la relación entre praxis y materialidad a partir de la diferenciación entre razón analítica y razón dialéctica. En el segundo, se expondrá la forma en que Sartre piensa la doble dimensión de la historia: es decir, como actividad y como pasividad, como aquello que los hombres hacen y como aquello que los hombres sufren. La historia sufrida se presenta como la materia que, en su inercia, les arrebata a los hombres su propio trabajo, volviéndolo una fuerza exógena a ellos mismos. En el tercero, se intentará elucidar el sentido de la definición sartreana acerca de que la aventura humana es una lucha contra la rareté a partir de la definición de la rareté como negatividad que totaliza las relaciones del hombre con la naturaleza y del hombre con el hombre. En el cuarto y último apartado, me dedicaré a abordar cómo, desde una dialéctica exteriorización-interiorización, la violencia se define bajo la forma de un maniqueísmo propio de la rareté que hace del otro un posible anti-hombre y en donde la muerte es el absoluto insuperable.

\section{PRAXIS Y MATERIALIDAD}

En Las aventuras de la dialéctica, Merleau-Ponty señala que una de las principales diferencias entre el pensamiento de Sartre y el de Marx es la adhesión del primero hacia el cogito cartesiano: «lo que distingue a Sartre del marxismo, aún en su periodo actual, es en todo caso su filosofía del

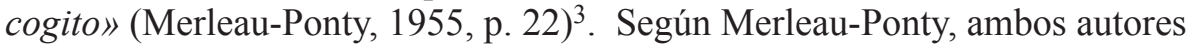
consideran que la intersubjetividad posee un sentido fuertemente agonal; sin embargo, la diferencia estribaría en que Marx piensa el conflicto en términos histórico-políticos, mientras que Sartre lo haría a partir de su comprensión

3 Con respecto al «aún en su periodo actual», Merleau-Ponty se refiere al momento de acercamiento de Sartre con el Partido Comunista Francés. Gran parte de Las aventuras de a dialéctica es una crítica a dicho acercamiento que se encuentra cristalizado en los artículos que conforman «Los comunistas y la paz» escritos por Sartre entre 1952 y 1954. 
de la conciencia como ser para-sí ${ }^{4}$. El autor de la Fenomenología de la percepción afirma que, en el caso de Marx, las relaciones entre los hombres están mediadas por la materia, mientras que, en el caso de Sartre, se trata de relaciones inmediatas de cogito a cogito ( $C f$. Merleau-Ponty 1955, p. 233).

Más allá de si Sartre tomó en cuenta la crítica de Merleau-Ponty en los años que van de una obra a la otra, o si se trata de otra cuestión, e, incluso si la crítica tiene un asidero real en las premisas de la obra de $1943^{5}$, cabe resaltar que, en la Crítica de la razón dialéctica, se afirma que las relaciones entre los hombres están mediadas por la materia. Tal es así que dentro de la lógica expuesta en esta obra, la materia es la primera totalización externa que reciben los hombres. Dicha totalización implica tanto su unificación como su separación. Esto significa que, en la Crítica de la razón dialéctica, la materia posee una importancia innegable.

En este aspecto, la diferencia con Engels y con lo que Sartre llama «marxismo contemporáneo» ${ }^{6}$ es fundamental a la hora de comprender el rol que ocupa la materia dentro del despliegue dialéctico de la historia humana. Sartre le crítica a Engels el hecho de llevar a cabo en la materia y en el mundo natural una hipostasis de lo acontecido en el mundo humano. La tesis de Engels sobre las tres leyes de la dialéctica y la forma en que esta opera en

4 En este aspecto, resulta interesante destacar que en el artículo «La querella del existencialismo» (Merleau-Ponty, 1963, pp. 125-144), Merleau-Ponty había llevado a cabo una defensa de Sartre frente a las críticas provenientes del catolicismo y del marxismo. Sin embargo, en Las aventuras de la dialéctica, Merleau-Ponty se refiere a otra cosa. En «La querella del existencialismo» Merleau-Ponty se refería a un marxismo objetivista que estaba más cerca del pensamiento iluminista del siglo XVIII que del de Marx. En el texto de 1955, Merleau-Ponty, en cambio, enfrenta el pensamiento de Sartre al de Marx y lo hace para señalar, no el hecho de que Sartre sostenga la irreductibilidad de la subjetividad a la objetividad, sino el supuesto subjetivismo extremo de Sartre. Para Merleau-Ponty, hay en Sartre un cartesianismo que lo vuelve incompatible con el pensamiento dialéctico de Marx.

5 Simone De Beauvoir en su texto Merleau-Ponty y el pseudosartrismo (publicado al español como J.P. Sartre vs. Merleau-Ponty) sostiene enfáticamente que la lectura merleaupontyana de la ontología expuesta por Sartre en El ser y la nada es absolutamente errada. Con respecto a la relación entre estas dos obras, mucho se ha escrito. Hay quienes sostienen que la Crítica implica una ruptura casi total con respecto al proyecto ontológico sartreano, cuyo mayor exponente es El ser y la nada, mientras que otros autores, en cambio, sostienen cierta línea de continuidad entre ambas obras. La ya mencionada obra de José Luís Rodríguez García Sartre. La pasión por la libertad es un ejemplo de la primera posición (Cf. Rodríguez 2004, pp. 10-16) mientras que el ya clásico texto de Wilfred Desan El marxismo de Jean Paul Sartre (Desan 1971, pp.20-32) y el artículo de Florence Caeymaex «La Crítica de la razón dialéctica: ¿una fenomenología de la praxis?».

6 A lo largo de la obra, Sartre emplea la expresión «marxismo contemporáneo» para referirse a un materialismo mecanicista que, según Sartre, tiene su origen en Engels y que, luego, se vio representado por la ideología oficial del PC y de la URSS. 
la naturaleza es vista por Sartre como un idealismo que, si bien se denomina a sí mismo como «materialismo», es más idealista que aquello a lo que dice combatir.

Como señala Carla Cordua, en su artículo «Sartre y la crítica a la filosofía de la historia», una de las diferencias fundamentales entre Engels y Sartre es el hecho de que, para este último, no existen leyes de la historia, mientras que, para el primero, la historia se encuentra regulada por leyes de la misma forma en que lo está la naturaleza ( $C f$. Cordua 1994, pp. 27-66). En efecto, tanto Engels como gran parte del marxismo de la primera mitad del siglo $\mathrm{XX}$, se habían propuesto, como objetivo central de sus trabajos teóricos, «desentrañar» las leyes de la historia, leyes que deberían poseer la misma universalidad y exactitud que las del mundo natural.

En torno a la cuestión de la negatividad, Sartre sostiene que hay una falacia en el ejemplo dado por Engels acerca de que la existencia, en el ámbito electromagnético, de polos positivos y polos negativos signifique una instancia de negatividad ya que en verdad se trata de dos positividades que se oponen. El hecho de que una sea denominada como «positiva» y otra como «negativa» se debe a una nomenclatura humana. La materia en sí no posee negatividad. Sin embargo, esto no significa ni que Sartre le quite importancia a la materia, ni que incurra en algún tipo de dualismo espiritualista. Por el contrario, Sartre brega por una legitimación del materialismo histórico y por una inteligibidad radical de la dialéctica materialista. «De hecho sabemos que la idea de dialéctica ha surgido en la Historia por muy diversos caminos, y que tanto Hegel como Marx la descubrieron y la definieron en las relaciones del hombre con la materia y en la de los hombres entre sí» (Sartre 1985, p. 148).

Sin embargo, para Sartre, no pueden existir ni resistencias ni fuerzas negativas más que en un movimiento que se realiza por el porvenir. La resistencia es resistencia a una integración. Sólo a partir de la praxis emerge la negatividad en el mundo. En este sentido, con respecto a la tesis de Spinoza de que «toda determinación es negación», Sartre sostendrá que esto es así sólo en el caso de que se considere la determinación como el aislamiento de lo determinado de la totalidad. La negación se encuentra constituida por la unidad primera. La parte determinada pertenece la totalidad ya que se exige que el todo esté presente en las partes; sin embargo, en tanto se aísla, ella no es el todo, por lo que niega a la totalidad y se niega, en consecuencia, a sí misma. Esta sería la primera negación propiamente dialéctica y Sartre la descubre como esencial del proceso de trabajo.

Retomando el concepto heideggeriano de útil, Sartre observa que cuando el hombre actúa en el mundo unifica el campo de utensilidad que se abre frente a él. Ese campo de utensilidad se presenta como una totalidad que es atravesada por el proyecto humano para separar las herramientas que utilizará 
con vistas a un fin determinado: el hombre retotaliza la totalidad preexistente. A diferencia de la instancia abstracta o biológica, en este nivel el hombre no se enfrenta a una dispersión molecular (es decir, a la Naturaleza que Sartre concibe que pura materia), sino a un totalidad preexistente; es decir que ya existe una totalidad pasiva que se reconfigura, o bien, por la acción directa del hombre o bien en virtud de las leyes propias de la exterioridad.

\section{LA DIMENSIÓN DEMONIACA DE LA HISTORIA: INERCIA Y ANTI-PRAXIS}

La praxis humana impone a la materia su sentido. Sartre comprende esta configuración del campo material a partir de un despliegue dialéctico que niega y totaliza lo que, en un primer momento, es pura dispersión. La negación y totalización implica el fundamento mismo de la dialéctica puesto que presenta la praxis como una negación de la negación que es una afirmación. La estructura misma de la praxis aparece constituida dialécticamente ya que articula interioridad y exterioridad en una misma unidad sintética. En este momento del despliegue dialéctico, los hombres se presentan como sujetos históricos, es decir la historia aparece como aquello que los hombres hacen.

Sin embargo, la historia posee también otra dimensión. En este aspecto, Sartre retoma explícitamente de la tesis de Marx acerca de que «los hombres hacen la historia pero en circunstancias que no eligen». La afirmación lleva in nuce la cuestión esencial de la historia: ella es, al mismo tiempo, lo que los hombres hacen y lo que los hombres sufren. Precisamente, Sartre encuentra en el pensamiento expuesto por Marx la complejidad del entramado histórico en toda su irreducible densidad. Efectivamente, los hombres hacen la historia, pero no es menos cierto que los hombres también la padecen. La historia guarda un doble sentido. Por un lado, es lo que hacen los hombres a través de su libre praxis, común o individual. «En efecto, la historia humana, orientación hacia el porvenir y conservación totalizadora del pasado, se define también en el presente como algo que les ocurre a los hombres» (Sartre 1985, p. 234). Sin embargo, el hecho de que la historia sea, además, algo que les ocurre a los hombres significa que el hombre es, por lo tanto, sujeto activo y pasivo de la historia.

La inteligibilidad de esta dualidad fáustica pone en juego la validez de la razón dialéctica. Si bien se trata de un factum, la condición de posibilidad de una racionalidad dialéctica se juega en la posibilidad de hacer inteligible esta aparente paradoja. En el apartado anterior se ha expuesto la forma en que la praxis implica una totalización dialéctica del mundo material, por lo que se señaló la dimensión activa del hombre en la historia. En este sentido, la primera parte de la sentencia de Marx encontraría su inteligibilidad. Sin embargo, la segunda parte de dicha sentencia también debe ser inteligible. 
Florence Cayemaex realiza una sugerente observación al arriesgar la tesis de una pervivencia del método fenomenológico en la Crítica de la razón dialéctica. Según Caeymaex, en su intento de volver inteligible la historia, Sartre lleva a cabo una fenomenología de la praxis como punto de partida metodológico (Cf. Caeymaex 2009, pp. 26-44). La descripción fenomenológica de la praxis humana abriría un horizonte a partir del cual podría comprenderse la dualidad del hombre en el sentido de quien hace la historia y de quien la sufre.

Si la materia era, pues, aquello que el hombre transformaba a partir de su praxis, la materia es también aquello que transforma a los hombres. El hombre totaliza la materia pero, de igual manera, la materia totaliza al hombre. La Historia se define en esta contradicción permanente en la que los hombres «hacen» y «son hechos». En la Crítica de la razón dialéctica, como ya se ha mencionado, la materia es la que totaliza a los hombres. En este sentido, Sartre sostiene que «[...] la materia es el motor pasivo de la historia» (Sartre 1985, p. 234).

Hablar de «motor pasivo» puede sonar a una contradicción formal. Sin embargo, para la inteligibilización y eliminación de esta contradicción formal, se necesita señalar dos cuestiones. La primera de ellas es que, a lo que se refiere Sartre, es al hecho de que la materia lleva a cabo una totalización sobre los hombres. La materia se vuelve un motor de la historia en tanto impone al hombre una totalización «sufrida». En esta totalización sufrida, los hombres se ven inmersos en un campo de materialidad que les impone una serie de necesidades no elegidas y que deben superar a partir de su libre praxis. La segunda cuestión se refiere al hecho de que, para Sartre, la totalización que la materia realiza sobre los hombres, si bien implica un movimiento de la materia, dicho movimiento no es inherente a ella per se. En este punto se ve claramente la diferencia entre Sartre y el «marxismo contemporáneo». Desde Engels en adelante, la escolástica marxista, ha comprendido el movimiento de la materia a partir de «leyes dialécticas» ${ }^{7}$ inherentes a sí mismas. Para Sartre, este posicionamiento es una metafísica determinista que concluye incluso en la idea del «eterno retorno» ${ }^{8}$.

$7 \quad$ En la Dialéctica de la naturaleza, Engels establece tres leyes fundamentales: la ley de conversión de la cantidad en cualidad y, viceversa, la ley de compenetración de los contrarios y la ley que pronuncia que toda negación de la negación es una afirmación (Engels 1983, pp.170177).

8 En el último párrafo de la Introducción a la Dialéctica de la naturaleza, Engels afirma que «[...] abrigamos la certidumbre de que la materia es eternamente la misma en todas sus transformaciones, que jamás puede perderse ninguno de sus atributos, y también, por lo tanto con la misma férrea necesidad con que exterminará en la tierra su más elevada creación, el cerebro pensante volverá a producirlo en alguna otra parte y momento» (Engels 1983, p.34). 
Sartre comprende el movimiento determinante de la materia sobre los hombres como un movimiento de retorno de la materia trabajada hacia y contra los mismos hombres. En este punto, se presenta lo «práctico-inerte» como instancia fundamental de una dialéctica materialista que no incurra en ningún tipo de mecanicismo determinista. Lo práctico-inerte es el resultado de la praxis que, tras sellar su sentido sobre la materia, adquiere una dinámica propia e impone al sujeto que llevó a cabo su libre praxis una determinación externa a él mismo. Se trata del fenómeno de alienación, el cual, para Sartre, no se limita únicamente a las sociedades capitalistas, sino que es un elemento constitutivo de la praxis y de la historia, tal como ellas se han dado a lo largo de la «aventura humana». La libre praxis engendra ella misma su propia negación a partir del surgimiento necesario de lo práctico-inerte, cuya dinámica esencial es la de emerger como «antipraxis».

El título de este apartado hace referencia a una definición que da el propio Sartre en lo concerniente a este momento de alienación con respecto a la propia praxis. El carácter «demoniaco» de la historia, obviamente, no se refiere a una instancia teológica ni tampoco moral, sino a aquello inhumano que surge desde el seno mismo de la materia trabajada por el hombre y adquiere un movimiento inercial que se opone a él.

La Historia tomada a este nivel ofrece un sentido terrible y desesperante, parece, en efecto, que los hombres están unidos por una negación inerte y demoniaca, que les toma su substancia (es decir su trabajo) para volverla contra todos bajo la forma de inercia activa y de totalización por exterminación (Sartre 1985, p.236).

La densidad de la cita arroja una serie de cuestiones que es necesario abordar. En un primer momento, la comprensión sartreana de la dimensión pasiva del hombre con respecto a la historia implica una negación del hombre y no una realización. A diferencia del discurso positivista decimonónico que concebía a la Historia como un desarrollo teleológico que, en cierta medida, trascendía las voluntades individuales pero, al mismo tiempo, implicaba una realización del hombre ${ }^{9}$, para Sartre la realización de la historia en tanto totalización sobre los hombres es una amenaza. El movimiento de la historia, en el sentido de historia sufrida, surge de la praxis humana para volverse

9 Las obras de Saint Simon y, sobre todo de Compte son representantes de este positivismo. Sin embargo, se trata de un discurso del cual se ha apropiado en gran medida el marxismo dogmático. El libro El desarrollo en la naturaleza y la sociedad es un buen ejemplo de ello. Se trata de un conjunto de artículos escritos por distintos autores soviéticos. En él se comienza con el desarrollo de la materia inorgánica para concluir en la Revolución. Todo el proceso sería una dialéctica cuyo primer momento (la formación de la materia inorgánica) ya estaría determinando el último (la Revolución). 
contra ellos. Se trata de una inercia activa, porque el movimiento le viene de otro, en este caso del hombre, y adquiere luego una dinámica autónoma.

En segundo lugar, la totalización que la historia lleva a cabo sobre los hombres significa la unión de los hombres por medio del peligro de eliminación. El retorno de la materia trabajada hacia los hombres se da bajo la forma de la preposición «contra». Los hombres reciben su unidad histórica a partir de la posibilidad de exterminación de todos y de cada uno. Esta unidad pasiva, recibida de forma externa luego es interiorizada y condiciona la relación con la materia y con los otros.

Vamos a ver que esta extraña relación -con la primera relación que de ella resulta- comporta su propia inteligibilidad dialéctica en cuanto se examina la relación de una multiplicidad de individuos con el campo práctico que los rodeo, en tanto que es para cada uno una relación unívoca de interioridad al unirla dialécticamente con las relaciones recíprocas que les unen (Sartre 1985, p.236).

\section{LA AVENTURA HUMANA COMO LUCHA CONTRA LA RARETÉ}

Según sus propias palabras, Sartre sostiene que Marx constituyó su concepción de la dialéctica «[...] a partir y contra de los economistas burgueses de la rareté» (Sartre 1985, p. 251). El filósofo francés, si bien continúa la formulación crítica de las concepciones economicistas burguesas de Marx, señala que, en el autor de El capital, no se presenta un intento por darle inteligibilidad al fenómeno, sino que hay, sobre todo, una formulación empírico-histórica del mismo. Precisamente, como se ha ido subrayando a lo largo del presente trabajo, el objetivo de Sartre es volver inteligible la praxis y la historia humanas. En este aspecto, la cuestión en torno a la rareté es fundamental, ya que el propio Sartre afirma que «toda la aventura humana es una lucha contra la rareté» (Sartre 1985, p. 237). La Historia humana, por lo tanto, aparece constituida a partir de la rareté, la cual se presenta como una estructura originaria que es condición de posibilidad de la propia historia.

La comprensión sartreana del carácter originario de la rareté exige llevar a cabo una aclaración. El propio Sartre señala que esta afirmación no equivale a decir que la rareté se trate de un a priori, por el contrario, se trata de un factum. Sostener que la historia humana se dé bajo el dominio de la rareté, no significa que no pueda haber en, por ejemplo, otro planeta una historia que no la tenga como núcleo, ni que la rareté no pueda ser superada en el futuro. La historia en tanto historia humana, tal como esta se ha dado, ha acontecido y acontece bajo el dominio de la rareté. Precisamente, la contingencia de la rareté es correlativa a la contingencia de la historia. En este aspecto, Sartre continúa manteniendo la misma estructura lógica de El ser y la nada, ya que, así como 
el ser para-sí era contingente pero en su contingencia emergía la necesidad, la historia humana tal como se ha dado, y tal como se da, es contingente, pero al ser esta historia es necesario que se haya dado de esa manera.

En el caso que nos ocupa, la rareté parece cada vez menos contingente en la medida en que engendramos nosotros mismos sus nuevas formas como medio de nuestra vida sobre la base de una contingencia original; si se quiere, se puede ver en ello la necesidad de nuestra contingencia o la contingencia de nuestra necesidad (Sartre 1985, p. 238).

A partir de la articulación entre necesidad y contingencia, la rareté determina históricamente el sentido agonal de las relaciones humanas. La rareté implica que no hay para todos.

En verdad, la rareté como tensión y como campo de fuerzas es la expresión de un hecho cuantitativo (más o menos rigurosamente definido): tal sustancia natural o tal producto manufacturado existe en cantidad insuficiente, en un campo social determinado, dado el número de miembros de los grupos o de los habitantes de la región, porque no hay bastante para todos (Sartre 1985, p. 238).

En este punto, cabe destacar la consideración que Rodríguez García realiza en su texto Jean-Paul Sartre. La pasión por la libertad (Rodríguez García 2004), consideración que es necesaria para evitar malentendidos a la hora de pensar la problemática de rareté en Sartre. El autor señala que, si bien, a primera vista, el planteo de Sartre puede parecer semejante al de $E l$ leviatán de Hobbes, en verdad se trata de planteos antagónicos. La definición hobbesiana del hombre como «lobo del hombre» se fundamenta en la idea de una naturaleza humana común, universal y compartida por todos. En cambio, en Sartre la comprensión del otro como posibilidad de negación de mi humanidad, se fundamenta en un determinado desarrollo histórico, y no en una definición de lo que el hombre es.

De igual manera, a diferencia de los economistas liberales, tal es Malthus uno de los ejemplos más notorios, la rareté no se presenta como un simple hecho, comprensible a partir de la racionalidad analítica en su faceta de cálculo «oferta-demanda» trasladada a la naturaleza, Sartre sostiene que la rareté le llega a la materia a partir del hombre. Es decir, hay «ausencia» en tanto un proyecto humano, a través de su libre praxis, totaliza y sella la materia. Aun así, esto no implica una concepción subjetivista de la rareté. A partir de lo señalado en los dos apartados anteriores de este trabajo, es comprensible que Sartre plantee la rareté como una relación dialéctica entre el hombre y la materia circundante. 
De la misma manera en que la rareté le llega a la materia por el hombre, les llega a los hombres por la materia. Se trata de una permanente tensión entre la praxis y la anti-praxis. Cuando el hombre sella la materia, cuando proyecta sobre ella una totalización en curso, la materia retorna al hombre como negatividad. En esa circularidad alienante, la rareté, emerge como estructura originaria de la historia.

Sartre define, en ese momento del despliegue de la racionalidad dialéctica, a la rareté como la unidad negativa de la multiplicidad de los hombres. La definición de unidad negativa dada por Sartre se refiere a que se trata de una unidad que les adviene a los hombres desde fuera. La materia totalizada vuelve hacia los hombres como posibilidad de destrucción. Esta posibilidad de destrucción se abre, por su parte, hacia dos direcciones complementarias. Por un lado, como peligro común, como amenaza de destrucción de todos. Por otro, como posibilidad de destrucción de cada uno por medio de la praxis del otro.

En este aspecto, cabe destacar que la rareté unifica y separa, al mismo tiempo, a los hombres. La totalización sufrida en el marco de la rareté hace que cada hombre sea una posible de negación de los otros hombres. Al «no haber suficiente», cada uno es un posible sobrante, lo que hace que el peligro de eliminación por medio de la praxis de los otros sea una amenaza constante. Cada uno es la amenaza permanente del otro. El otro es la posibilidad de mi negación, pero, de la misma manera, yo soy la posibilidad de negación del otro.

Sin lugar a dudas, en estas afirmaciones de Sartre, resuenan algunas de las tesis expuestas en El ser y la nada. Sin embargo, cabe destacar que, en la Crítica de la razón dialéctica, no se trata de una lógica de objetivación y subjetivación a partir de la imposibilidad de un encuentro de miradas, sino que la posibilidad de negación entre los hombres acontece a partir de un fenómeno histórico y no de una estructura ontológica del ser para-sí. Yo soy la posibilidad de negación del otro y el otro es mi posibilidad de negación a partir de la estructura originaria de la rareté. En este aspecto, el hombre aparece definido a partir de las determinaciones históricas que le atraviesen. Dentro de esas determinaciones, la rareté es la determinación fundamental, en tanto estructura originaria de la historia.

Como se ha señalado, la rareté hace de cada uno una constante amenaza para el otro. La materia que retorna hacia y contra los hombres los transforma en potenciales enemigos. En cada ser humano habita la inhumanidad ya que es la posibilidad de negación de la humanidad del otro. En el otro encuentro la inhumanidad en tanto su praxis, en el marco de la rareté, puede llevar a mi eliminación. De la misma manera, yo también poseo la potencialidad de lo inhumano, puesto que mi praxis puede ser la eliminación del otro. 


\section{VIOLENCIA Y MANIQUEÍSMO}

Si bien la determinación de la historia humana a partir de la rareté significa la separación y antagonismo entre los hombres, también implica una relación de reciprocidad entre ellos. En este sentido, vale señalar un paralelismo entre la obra de 1960 y la de 1943. Habitualmente, en cuanto a la problemática de la intersubjetividad, suele leerse el pensamiento de Sartre como un pensamiento de la no reciprocidad ya que el conflicto ocupa un lugar de gran relevancia ${ }^{10}$. Sin embargo, el conflicto implica, para Sartre, reciprocidad. En El ser y la nada, la imposibilidad de un reconocimiento recíproco era posible a partir del sentido ineluctablemente relacional del hombre en tanto es, al mismo tiempo, ser para-sí y ser para-otro. Sartre mismo señala que lo que me pasa a mí, también le pasa al otro ${ }^{11}$.

Desde esta perspectiva, la profundización en torno a la rareté como factum que abre la posibilidad de la historia descubre la formulación de la experiencia histórica como experiencia maniquea. Con el término «maniqueo», Sartre designa el fenómeno de la interiorización de la rareté el cual que tiene por correlato la constitución de una ética donde el bien y el mal adquieren un sentido absoluto. «Consideramos, pues, en el nivel mismo de la necesidad y por la necesidad, que la rareté se vive prácticamente por la acción maniquea y que la ética se manifiesta como imperativo destructivo: hay que destruir el mal» (Sartre 198, p. 244). Como se ha visto, la rareté impone una lógica binaria en las relaciones intersubjetivas a partir de la oposición hombre/antihombre. Esa oposición conlleva una práctica maniquea que se realiza en una ética que determina el Bien como la preservación de la humanidad, lo que significa la destrucción del Mal, es decir de la amenaza a la humanidad.

Sin embargo, lo que se experimenta como humanidad es la propia humanidad, mientras que la inhumanidad, desde la propia perspectiva, es el otro. Desde este maniqueísmo, la violencia emerge como «interiorización de la rareté». A partir de este fenómeno, la ética experienciada se configura a partir de la violencia como realización práctica de la rareté. En una historia en

10 En el artículo «La intersubjetividad en El ser y la nada de Sartre», por ejemplo, se contrapone la forma en que Sartre y Heidegger comprenden el sentido originario de la relación con el otro. Zahavi observa que, si bien Sartre retoma algunos de los planteos heideggerianos en torno a la forma en que el mundo siempre me refiere a los otros, el filósofo francés criticará la tesis central de Heidegger acerca del Mitsein. Zahavi señala que la oposición fundamental entre Heidegger y Sartre, a la hora de pensar el sentido originario de la relación con el otro, se funda en que, para el primero, este sentido radica en la idea de «equipo», mientras que, para el segundo, como se ha visto, radica en la idea de «conflicto» (Cf. Zahavi 2004, pp. 265-269).

11 En El ser y la nada, cuando Sartre habla de la dimensión ontológica del cuerpo como ser para otro sostiene que las estructuras ontológicas mías y del otro son las mismas. 
la que cada uno es el peligro de aniquilación del otro, la violencia adquiere un sentido universal. «Esta violencia del Otro sólo es una realidad objetiva en la medida que existe en todos como motivación universal de la contraviolencia» (Sartre 1985, p. 245). Con estas palabras, Sartre observa que la reciprocidad de las relaciones humanas en un sistema material concreto se da como motivación universal en tanto cada uno es para el otro un peligro de eliminación. Es por ello que la violencia se presenta siempre como «contraviolencia», pues el otro es, al menos potencialmente, una amenaza.

En el segundo tomo de la Crítica de la razón dialéctica, Sartre aborda, con mayor profundidad aún, la génesis de la ética a partir de la realización práctica de la rareté como maniqueísmo. En tanto cada uno ve en el otro su posible eliminación, el Bien se constituye como todo aquello que preserve mi humanidad. Sartre observa la forma en que la fuerza es concebida como un valor moral en tanto ella me puede servir para preservarme frente al peligro de eliminación. «[...] en el maniqueísmo de la rareté, la violencia está al servicio del Bien, ella es el Bien mismo; el individuo (y el grupo también) asimila su dignidad de hombre en la contraviolencia que la sostiene. Toma así el nombre de fuerza» (Sartre 1985, p. 33). El Bien se presenta como la propia preservación y eso implica la negación, o posibilidad de negación, del otro ya que ese otro es el que me niega o puede hacerlo. La dignidad de hombre se revela así en una doble vía. La primera, como hecho fundado en la contraviolencia. La segunda como imperativo moral: «el hombre debe ser fuerte» (Sartre 1985, p.33).

La reciprocidad del sistema maniqueo sobre el que se funda la violencia se encuentra instituido sobre la diferencia absoluta entre la vida y la muerte. Toda violencia, en sus diferentes grados, se instaura sobre el límite entre la vida y la muerte. En este punto, el propio Sartre reinterpreta sus propias tesis de 1943.

Nos retrotraemos aquí a lo dicho en El ser y la nada: el relativismo es una actitud histórica que no puede fundarse más que sobre el carácter de la vida cotidiana e inmediata $o$, en otros términos, lo relativo es ininteligible si, antes de ser relativo de otros relativos, no es relativo a un absoluto. Pero falta comprender este absoluto [...]. Lo absoluto, es sobre todo, la diferencia que separa la vida de la muerte [...]; es el corte entre la existencia y la nada [...] (Sartre 1985, p. 40).

La diferencia entre la vida y la muerte ${ }^{12}$ se presenta como lo absoluto a lo que toda actitud frente al otro es relativo: hay un sentido ontológico

12 Aquí debe remarcarse que la reinterpretación que realiza el propio Sartre acerca de su pensamiento anterior deja ver un cambio de perspectiva. En El ser y la nada, no hay una equiparación entre el no-ser con la muertes y de la vida con la existencia. La oposición esencial 
en esa diferencia ya que se trata de la oposición entre existencia y nada. Sin embargo, dicho sentido ontológico surge de la facticidad de una historia marcada por la rareté; es decir, no se trata de un a priori. Cada uno se enfrenta al otro como posibilidad de muerte, lo que, como se ha dicho, instaura un maniqueismo moral donde, para cada uno, el Bien es identificado como la propia preservación.

En su «Nota a Maquiavelo», Merleau-Ponty habla de una «Comunión de Santos negra». La construcción semántica bien puede describir el planteo de Sartre, ya que hay una reciprocidad entre los hombres. La circularidad demoniaca que la materia impone, en su movimiento de retorno, unifica a los hombres en una relación agonal donde el otro es potencial peligro de eliminación. Bajo el dominio de la rareté, el maniqueismo emerge como la moral originaria de la historia y esa moral es vivida por cada uno en el modo de una experiencia totalizadora. Cada acción se refiere al otro a partir de la posible transición de la existencia a la nada. El Bien y el Mal se presentan como términos absolutos desde los cuales las relaciones intersubjetivas se experimentan en su más descarnada densidad. En la experiencia vivida, toda violencia es una contraviolencia porque ya la existencia del otro es una amenaza para la propia vida.

\section{CONCLUSIÓN}

En la Crítica de la razón dialéctica la problematización sartreana en torno a la violencia se circuncribe sobre un horizonte teórico que hace de la rareté uno de los elementos fundacionales de la historia humana tal como esta se ha presentado facticamente. En este sentido, la violencia no es instituida a partir de una estructura ontológica del para-sí, pero tampoco es una actitud frente al otro que pueda ser inteligibilizada analiticamente como una dimensión escindida de la totalidad.

Ahora bien, cabe preguntarse acerca de la alternativa a la violencia que podría presentar Sartre en esta obra. El fin de la violencia sólo sería posible a partir de la erradicación de la rareté. Sin embargo, Sartre se muestra algo escéptico sobre este punto. Al comprender que la rareté no es un fenómeno específico de las sociedades capitales, la superación del capitalismo no implica la superación de la rareté $y$, por tanto, no implica tampoco la superación de la violencia. Aun apoyando sistemas sociales no capitalistas, como la China maoista, el filósofo francés señala que aún en estas sociedades sigue vigente la comprensión del otro como posibilidad de eliminación.

Aclarando que se trata de un texto inacabado, la Crítica no presenta una

de la obra de 1943 es entre ser para-sí y ser en sí. El ser para-sí está considerado como no ser y se define explicitamente como aquello que es lo que no es y no es lo que es ( $C f$. Sartre 1943, p. 33). 
alternativa al problema de la violencia y a la lógica deshumanizante de una historia marcada por la rareté. Sólo muchos años después, Sartre esbozará algunas vías alternativas que podrían significar la superación de la violencia y la realización de una humanidad plenamente humana. Paradójicamente, esta vía sería la ética. Claro está que no se trata de la ética maniquea de la que se habló en este trabajo ${ }^{13}$, sino de una ética que se presenta fundada en la esperanza de una humanidad donde cada uno es reconocido. En La esperanza ahora Sartre retoma algunas propuestas del mesianismo judío para intentar vislumbrar el fin de la violencia como posibilidad futura a partir de una transformación ética de la humanidad que se deslinde de las lógicas reificantes de la historia.

A pesar de los cambios entre un momento y otro del pensamiento sartreano, aún en la Esperanza ahora como en la Crítica, la violencia es factor constitutivo de la historia y la humanidad no es una humanidad realizada, sino que en el seno mismo de lo humano habita lo inhumano en tanto amenaza recíproca de eliminación.

\section{REFERENCIAS BIBLIOGRÁFICAS}

AUTORES VARIOS, 1962, El desarrollo en la naturaleza y la sociedad. Buenos Aires: Platina, tr. de Guilermo Silkin.

BUTLER. J., «Violence, Non-Violence: Sartre on Fanon», Graduate Faculty Philosophy Journal 27:1 (2006), pp. 3-24.

CAYEMAEX, F., «Le Critique de la raison dialectique: une phénoménologie de la praxis», Alter. Revué de phénoménologie, (2009), pp. 29-44.

CORDUA, C., "Sartre y la crítica a la filosofía de la historia», Gerencia del tiempo: Ensayos sobre Sartre (1994), pp. 27-66.

DESAN, W., 1965, The marxism of Jean-Paul Sartre. Nueva York: Doubleday and Company.

DE BEAUVOIR, S., 1963, J. P. Sartre versus Merleau-Ponty. Buenos Aires, Siglo XXI, tr. de Aníbal Leal.

ENGELS, F., 1983, Dialéctica de la naturaleza. Buenos Aires: Cartago, tr. de Floreal Mazia.

JEANSON, F., 1968, El problema moral y e pensamiento de Sartre. Madrid: Siglo $\mathrm{XX}$, tr. de Alfredo Llanos.

MERLEAU-PONTY, M., 1955, Les aventures de la dialectique. Paris: Gallimard.

13 Tampoco se trata de la moral planteada en los Cuadernos para una moral, texto sobre el que no se ha expuesto en este trabajo debido a una cuestión de extensión, además del hecho de que se trata de una problemática que trasciende los objetivos del presente estudio. Por otro lado, sobre el problema moral en el llamado «momento existencialista» de Sartre, se recomienda el ya clásico texto de Francis Jeason El problema moral y el pensamiento de Sartre. 
MERLEAU-POONTY, M., 1963, Sens et non-sens, Paris: Nagel.

PÉREZ LINDO, A., 2001, Acción e inercia social en el existencialismo dialéctico de J. P. Sartre. Buenos Aires: Del Signo.

RODRIGUEZ GARCIA, J. L., 2004, Jean Paul Sartre. La pasión por la libertad,. Barcelona: Bellaterra.

SARTRE, J.P., 2004, Crítica de la razón dialéctica. Tomo I, Buenos Aires: Losada, tr. de Manuel Lamana.

SARTRE, J.P., 1985, Critique de la Raison dialectique. Tome I. Théorie des ensemblee pratiques. Paris: Gallimard.

SARTRE, J.P., 1985, Critique de la raison dialectique. Tome II (inachevé). L'intgelligilibite de l. Historie. Paris: Gallimard

SARTRE, J.P., 1943, L'être et le néant. Essai d'ontologie phénoménologique. Paris: Gallimard.

SARTRE, J.P., 1964, Situations, VI. Problèmes du marxisme, 1. Paris: Gallimard.

SARTRE, J. P. 2006, La esperanza ahora. Madrid: Arena Libros, tr. de Isidro Herrera.

ZAHAVI, D., Intersubjectivite in Sartre's Being and Nothingness, Alter. Revue de Phénoménologie. Sartre fénoménologigue, (2002), pp. 265-284

Maximiliano Basilio Cladakis es profesor adjunto de la Cátedra de Filosofía de la Cultura de la Universidad Nacional de San Martín (Argentina) e investigador asistente del CONICET.

Líneas de Investigación:

Fenomenología francesa de posguerra, principalmente en las obras de Jean Paul Sartre y Maurice Merleau-Ponty.

Publicaciones recientes:

(2017): «Negatividad e intersubjetividad: la dimensión originaria del conflicto en

Kojève y en Sartre», Ideas y Valores, 66 (165).

(2017): «Merleau-Ponty y la encrucijada maquiaveliana», Symploké 7.

Correo electrónico: maxicladakis@yaoo.com.ar 